\title{
viewpoint
}

\section{Genomics in school}

\author{
SSS Science \& Society Series on Convergence Research
}

\author{
Roald Verhoeff, Dirk Jan Boerwinkel \& Arend Jan Waarlo
}

S chool curricula always lag behind scientific innovations; modern science has made so many great advances that the quantity of 'basic' science to be taught in the classroom increases year on year. Major breakthroughs and new research are obvious in a range of scientific disciplines, including medicine, forensics, biofuels, vaccine research and the mitigation of pollution (NGl, 2006). Moreover, fundamental biological concepts and practices have themselves advanced and school curricula need to be revised; for example, in evolutionary biology (Moore, 2007), probable evolutionary relationships are now being constructed by comparing proteins and genome sequences between organisms, rather than by searching for similarities in anatomy, embryology and physiology.

\section{...modern science has made so many great advances that the quantity of 'basic' science to be taught in the classroom increases year on year}

The conceptual and practical changes that have taken place in scientific theory and research in relation to genomics have also not yet found their place in the science curriculum, at least not in the Netherlands. It is now a few years since the publication of the human genome, and genomics research is continually generating large and complex data sets that have transformed the study of virtually all life processes (Collins, 2003). Despite this, and although a range of outreach programmes offer a temporary solution, such as the Dutch 'mobile DNA labs' (van Mil, 2007), greater efforts are needed to embed genomics into the standard science curriculum.
Two important characteristics of genomics are immediately apparent for inclusion in new educational materials. First, genomics combines the expertise and techniques of many disciplines-for example, molecular biology, physical sciences and bioinformatics - in order to study genomeenvironment interactions in relation to phenomena at many biological levels from the molecular up to that of patient communities or ecosystems. Second, genomics research programmes are often accompanied by studies of the ethical, legal and social aspects (ELSA) of the research; a trend that began with the Human Genome Project, which allocated a significant amount of its funding to studying the ELSA of the human genome sequence (Kitcher, 2001).

$\mathrm{O}$ ur task, as educational researchers within the Dutch network of the Centre for Society \& Genomics (CSG; Nijmegen, the Netherlands) is to connect secondary science education with scientific advances in genomics, as well as the implications of this new knowledge for society. The Netherlands Genomics Initiative, based at The Hague, has assigned $€ 32$ million for ELSA research for the period of 2004-2012, including funding for our project related to the mobile DNA labs. Both the distribution of the money and the research conducted are coordinated by the CSG (see also Stegmaier, this issue).

Yet, incorporating genomics education into the curriculum cannot be achieved by simply adding new content. Our studies of current biology education in the Netherlands clearly show that the Dutch science curriculum is already overloaded with scientific concepts (Verhoeff, 2003). In fact, the problem of cognitive overload, combined with a lack of coherence and relevance with regard to the content matter, has stimulated proposals for restructuring biology education. In response, the Dutch Biology Curriculum Innovation Board (CVBO, Utrecht) has adopted a concept-context approach to design biology education based on existing academic, professional or everyday life practices (Bennet et al, 2006). Our project connects to the concept-context approach by starting from cancer diagnosis practices and aims to answer the question that we elaborate here: how can genomics be embedded into the biology curriculum without adding to the problem of curricular overcrowding?

In selecting relevant curriculum content, three determinants must be balanced: science, student and society. To empower future citizens, biology education should promote biological thinking and the acquisition of life skills, such as being able to make informed decisions about genetic testing. Our project DNA labs for Citizenship includes designing exemplary teaching materials, organizing teachertraining activities around the mobile DNA labs and formulating curriculum proposals about genomics.

Here, we seek to achieve three things. First, we elaborate on the problem of the overcrowded biology curriculum in the Netherlands; second, we explore the issues of complexity and the societal impact of genomics research; and finally, we examine the possibility of using the tools of systems biology as a means to embed genomics into curricula without increasing overcrowding, yet, enhancing overall coherence.

recent survey of 22 countries indi-
cated that systems biology is not
explicitly mentioned in any science
curriculum in Europe (Moore, 2007); in addi-
tion, the principles of bioinformatics - an 
important discipline within genomics-are mentioned in very few. However, the exclusion of systems biology is not a unique oversight; the introduction of new scientific concepts and techniques into science education is hampered in general by the problem of curricular overcrowding. Current European biology curricula cover many themes in a descriptive manner, each of which brings a large number of new concepts involved at various levels of biological organization. In the Netherlands, for example, an average school textbook introduces no less than 577 new concepts related to cell biology alone, which illustrates that the curriculum is extremely heavy on factual content.

To investigate the extent of this information overload, we analysed the contents of two Dutch textbooks that constitute the method 'Biologie voor jou' ('Biology for you'), which is used to teach pre-university biology by approximately $40 \%$ of biology teachers (Smits \& Waas, 2000). The first chapter consists of an 'introduction to biology' as an empirical discipline and it explains the structural organization of organisms in terms of organs, tissues and cells. In addition, the submicroscopic structure of plant and animal cells is elaborated on in detail. Subsequent chapters focus on topics such as reproduction and development, genetics, DNA, homeostasis, behaviour and the immune system. As a focus for our analysis, we selected the topic of cell biology and classified cell biological concepts - that is, concepts connected to the theme of 'the cell'-according to three main categories representing the molecular, cellular and organismic levels (Verhoeff, 2003). Each new cell biology concept mentioned for the first time in the text or in the legends of figures was scored and checked for whether it was only mentioned, or if it was also explained to the reader in terms of his or her prior knowledge.

Table 1 presents the results of the analysis. At the molecular level, the concepts presented in the textbooks cover topics including chemical compounds, chemical reactions - such as phosphorylation or polymerization-and molecular characteristics such as fat solubility and oxidation. At the cellular level, the concepts range from substances-hormones and nutrients, for example-to processes such as diffusion or active transport, as well as cellular structures and their functions. At the organismic level, the concepts relate to bodily processes, structures-both organs and artificial replacements - and organism characteristics

Table 1 The number of cell biological concepts introduced in the method 'Biology for you'

\begin{tabular}{llll}
\hline $\begin{array}{l}\text { Cell biological } \\
\text { concepts }(\boldsymbol{n}=\mathbf{5 7 7})\end{array}$ & $\begin{array}{l}\text { Number of new } \\
\text { concepts }\end{array}$ & $\begin{array}{l}\text { Percentage of concepts } \\
\text { coupled with explanation } \\
(\%)\end{array}$ & $\begin{array}{l}\text { Percentage of concepts } \\
\text { used after introduction } \\
\text { and explanation }(\%)\end{array}$ \\
\hline Molecular level & 141 & 70 & 9 \\
\hline Cellular level & 357 & 77 & 19 \\
\hline Organismic level & 79 & 61 & 14 \\
\hline
\end{tabular}

within the context of cell biology such as phenotypes, zygosity and trophism.

A s cell biology is not a part of the students' everyday lives, it is remarkable that around $64 \%$ of the cell biology concepts presented in the textbooks are not explained in terms of the students' prior knowledge (Table 1). Moreover, there are a significant number of cell biology concepts that are mentioned but not referred to-and are thus not required-later when topics such as genetics or metabolism are covered. In addition, although the cellular and subcellular levels are covered in detail, the number of concepts introduced at the organism level is relatively small, which indicates that the relationship between the cellular level and phenomena at higher levels of biological organization receives little attention. In fact, a closer look at the content of the curriculum of 'Biology for you' suggests that the focus is primarily on the structural characteristics of the cell, with scant attention paid to the dynamic aspects of cellular processes and signalling networks.

Clearly, a gap exists between academic research practices and the information disseminated by our pre-university education system. In the light of this, a re-thinking of the 'essential' biological concepts might actually reduce the cognitive load of the curriculum, which could then provide space for the inclusion of modern developments in the life sciences. However, the inclusion of genomics would also imply the introduction of another conceptual focusone that gives credit to both the complexity of the topic and the societal implications of contemporary research practices.

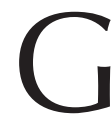
enomics focuses on understanding the relationship between large networks of genes and/or gene products, and the behaviour of the system being studied: for example, metabolic pathways, cellular responses, development or biodiversity. Genomics research has changed several scientific concepts about the functional and complex relationships between an organism's DNA, its environment and the resulting expression of certain characteristics. For example, many diseases are not caused by a single gene mutation; they arise from a complex interplay between environmental factors and multiple 'low-penetrance' predisposition gene variants (Balmain et al, 2003). Another conceptual change has been the understanding that the genome is not an unchangeable chain of genes, but is rather a complex system that interacts in many ways with the environment.

Genomics contributes to the relatively new field of systems biology, which focuses on the systematic study of complex and dynamic interactions in biological systems. The enormous complexity of this task demands collaboration between various scientific disciplines, ranging from biology and chemistry to mathematics, informatics and physics. Indeed, molecular technologies and bioinformatics have resulted in a shift from a single-gene-oriented approachso-called gene hunting-to genome-wide studies or 'fishing for genes in a data pool'. This has entailed the analysis of large and complex data sets to find the characteristic molecular alterations that determine either functional characteristics, such as those for disease risk or suitability for treatment (Balmain et al, 2003), or markers that can be used for the identification of genes. This might be used, for example, to develop genetic tests, for the identification of individuals in forensic science, the identification of species in metagenomics research, or for the analysis of the migratory patterns of mankind (Wells, 2006).

$\mathrm{N}$ ew genomics technologies have an impact on medical, administrative, industrial and agricultural practices, all of which involve and affect many societal stakeholders. These stakeholders, in turn, have gained increasing influence over the scientific agenda-either through 
financial support for research or by providing societal problems to address. An example is the Dutch Celiac Disease Consortium, which brings together industry, universities and the patient community to develop safer foods and more effective diagnosis, prevention and treatment of celiac disease. Knowledge can therefore be viewed as a social construct and scientific progress can be regarded as the result of a continuous interaction process, in which many stakeholders are involved (Latour 1987; Nowotny et al, 2001). In recent years, scientists have become more aware of the societal implications of their work and, in modern 'science \& society' activities, there is a tendency to allow scientists and lay experts to participate as equal partners in communication processes (van der Auweraert, 2004; Miller, 2001). The content of these processes includes a range of contextualized knowledge-academic, professional and experiential—with the aim of creating public dialogue to democratize and improve the transparency of decision-making in scientific research, which is required to embed science in society and gain public trust.

\section{...a gap exists between academic research practices and the information disseminated by our pre-university education system}

For example, in order to conduct socially robust cancer genomics research, real-world knowledge and the morally weighted insight of citizens, including cancer patients, should be taken into account. Such a requirement is not self-evident to the biomedical research community, however, as it is traditionally rather resistant to patient participation, based partly on the belief that the 'lay' community lacks the competencies to be involved in decision processes (Boote et al, 2002; Caron-Flinterman, 2005). The Dutch Council for Social Development (RMO; The Hague, the Netherlands) also concludes that, in the societal debate on human genetics, the medical genetic discourse is dominant. The council strongly recommends that this debate be supplemented with 'social participative discourse' and that more emphasis be given to the consequences of human genetics developments in terms of life quality (RMO, 2004).

To prepare both future citizens and future scientists for these types of debate, both genomics and systems biology should be a prominent part of the high school curriculum. In pre-professional training, students should be prepared for research themes in which complex interactions are studied using new genomics tools. In general, science education should provide every citizen with a basic view of the genome, as well as the personal and societal implications that might arise from knowing a person's genetic identity. Both groups should be prepared to take part in public debates and democratic decision-making about issues surrounding genomic research, such as direct-to-consumer genetic tests, which have raised questions about the clinical use of these tests, the need for regulation and the possible overconsumption of medical services (Sense about Science Trust, 2008).

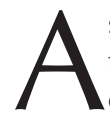
s part of their obligation to address the ethical, legal and social aspects of their research, five genomics centres of excellence in the Netherlands together developed a series of mobile DNA labs that can be taken to secondary schools to give students a realistic impression of the use of genomics in a societal context. Since January 2006, these labs have been offered free of charge to all Dutch secondary schools, and each lab focuses on a different practical context of genomics research. The DNA lab Tumor Talk, for example, developed by the Cancer Genomics Centre, focuses on the diagnosis and treatment of cancer (van Mil, 2007). Each of the four-hour educational modules includes a two-hour practical lab, allowing students to carry out 'hands-on' experiments using modern, advanced research equipment. In the course of the lab, university students

\section{SSS Science \& Society Series on Convergence Research}

This article is part of the EMBO reports Science \& Society Series on Convergence Research, which features Viewpoints from authors who attended the 'Doing Society and Genomics-Convergence and Competence Building' workshop organized by Peter Stegmaier for the Centre for Society and Genomics at Radboud University (Nijmegen, the Netherlands) in September 2008. We hope that this Viewpoint series will help to introduce our readers to the new multi- and transdisciplinary developments among the life sciences and the social sciences and humanities.

supervise the school students as they isolate DNA from a rat's thymus, perform PCR and use bioinformatic tools to analyse protein structures.

All five DNA labs have been evaluated together and have proven successful (Knippels et al, 2006). Teachers and students are enthusiastic about what they learn, and subsequently develop a positive attitude towards genomics research. The success of the initiative is most obviously reflected in the number of schools that have visited the website and have ordered the DNA lab Tumor Talk. Since September 2005, Tumor Talk has been fully booked and more than 17,000 students in 700 classes have been involved. However, the perceived learning outcomes are modest; students comment that they are able to grasp the how and why of genomics research, but seem to learn little about the functioning of and relationship between DNA, genes, proteins and phenomena at higher levels of organization. In addition, the initiative's aim to encourage the formation of opinions about genomics research, as well as to stimulate the discussion of societal issues in the classroom, has not been achieved.

These facts have therefore given cause for a revision of the DNA labs programme, embedded in an educational research project entitled DNA labs for Citizenship. The revision should improve both the students' insight into the complexity of the interrelations, and each student's competence in dealing with societal issues related to genomics. Another important reason for the revision is to prepare for the inclusion of genomics education into the biology curriculum. In the ongoing revision process, systems thinking has a fundamental role.

W e would therefore like to present systems thinking as a possible way to achieve the inclusion of genomics into science curricula. Systems thinking is linked with, but not identical to, systems biology. Systems biology refers to the integration of experimental and computational approaches to understand and predict complex cellular functions (Alberghina, 2007). One important characteristic of systems biology is that it is an iterative process of data-driven model building and model-driven data gathering. Although some scholars include the study of ecosystems in systems biology (Moore, 2007), the majority of current articles concern only molecular and cellular interactions. 


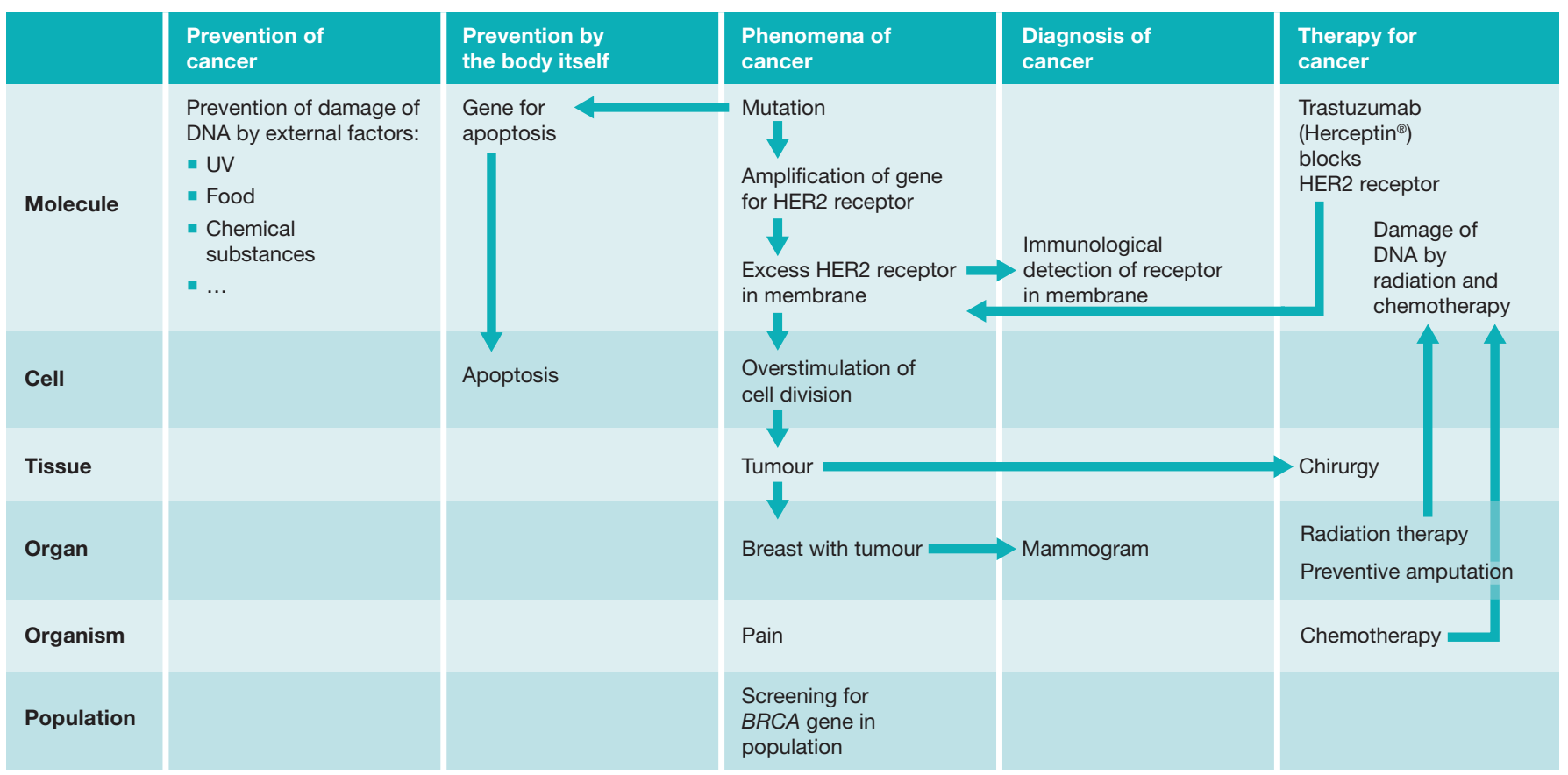

Fig 1 A matrix to organize and construct students' knowledge about cancer genomics

In fact, systems thinking in biology has a much longer history than the recent use of the term systems biology in academic research. In the 1930s, Ludwig Von Bertalanffy had already articulated his 'general systems theory' as a transdisciplinary approach to the study of the complex physical and chemical organization of life (Von Bertalanffy, 1968), and his 'holistic' approach has been fairly influential in biology education. Systems thinking has also been proposed as a metacognitive tool (Schaefer, 1989) and is one of the skills required by the Dutch examination syllabus for biology; students should be able to demonstrate an understanding that biological relations are complex by nature and often cannot be explained in a monocausal way. They should also be able to relate biological phenomena at various levels of organization to one another.

However, few educational materials have been developed to implement systems thinking in biology education. Knippels (2002) proposed a strategy based on systems thinking for genetics education: the "yo-yo strategy". The yo-yo strategy copes with complexity by explicitly distinguishing the levels of biological organization, and by descending and ascending these levels, starting from the concrete organismic level. Explicating the levels makes the transect nature of genetics transparent to students and provides an insight into what hereditary phenomena, processes and structures occur at the different levels of biological organization.

$\mathrm{n}$ a study in which systems thinking was explicitly introduced to cell biology education, Verhoeff et al (2008) described four elements of a systems thinking competence (Sidebar A). The aim of the study was to teach systems thinking as a metacognitive tool. By going through the process of systems modelling, students were introduced to the scientific practice of developing and using models as tools for observation, exploration and the prediction of biological phenomena. In this way, a systems approach not only helped students to learn about biological systems at different levels of organization, but also fostered an understanding of the nature of science that is largely concerned with extending and refining systems models.

Indeed, although educational or student models vary in many respects from scientific genomics models, we nevertheless see that an iterative process of modelling and testing is possible in education, and can prepare students for a strategy that they will later encounter in studies in which systems biology has a role.
Sidebar A $\mid$ The four elements of a systems thinking competence for biology education (Verhoeff et al, 2008)

(i) Being able to distinguish between the various levels of organization-that is, cell, organ and organism - and to match biological concepts with specific levels of biological organization

(ii) Being able to interrelate concepts at a specific level of organization (horizontal coherence)

(iii) Being able to link biology concepts from different levels of organization (vertical coherence)

(iv) Being able to think back and forth between abstract visualizations (models) to real biological phenomena

Accepting that systems thinking ought to be a major component of the upper secondary school biology curriculum obviously has implications for the content and structure of the entire biology curriculum. At present, several topics in the Dutch biology curriculum-cell biology, behaviour and ecology, for example-are limited to only one level of biological organization; systems thinking requires that topics be defined to cover different levels of biological organization. Fig 1, which shows an example of how systems thinking has been applied to genomics education, illustrates 
how cancer genomics represents a topic that transcends organizational levels from the molecular up to the societal.

B ut, how can systems thinking diminish the overcrowding of the biology curriculum? The answer is that overcrowding has a lot to do with coherence. A story can be overcrowded with details, but its details can be remembered through its characters and their interaction throughout the plot. By building a structure of horizontal and vertical relationships, the students construct a framework in which they can place new concepts. The use of this framework as a so-called "advanced organizer" improves retention (Ausubel, 1968). Systems thinking also requires the separation of central concepts from peripheral ones, meaning that fewer concepts need be learnt by heart because the framework indicates how and where information can be found. In genomics, for example, the gene is a central concept that will appear many times. As Knippels (2002) has proven, tuning the genetics vocabulary to the specific level that students are dealing with at any given moment prevents confusion. Explicitly distinguishing levels of organization therefore helps to prevent the often reported difficulties that students have with cytological concepts, chromosome structure and the homologous chromosome concept.

Systems thinking allows students to frame their knowledge in a matrix that includes a broad range of distinct organizational levels from the molecular up to and including the societal or population level (Fig 1). In this matrix, concepts and arrows are placed to indicate horizontal relationsfor example, between phenomena and therapy - and vertical relations-for example, between growth receptor, cell division and tumour. In this way, students organize their knowledge and generate questions and hypotheses about causes, treatments and prevention in a manner that is consistent with the systems biology approach in cancer genomics.

This approach covers the first three of the four elements of systems thinking competence listed in Sidebar A. The fourth element, however-the back and forth thinking between various types of models and real phenomena-requires another type of learning. Processes in molecular biology are difficult to imagine and the student should be challenged to use visualizations and other models to construct knowledge in a so-called model-based learning trajectory (Clement, 2000). In fact, a CSG research project started recently at our institute to investigate how genomics experts use imagery to handle the dynamic nature of molecular processes and how this might inform genomics education. We hope to be able to report soon the successful progress of this initiative.

\section{ACKNOWLEDGEMENTS}

This work was supported by grants from the Netherlands Genomics Initiative/Netherlands Organisation for Scientific Research (NWO).

\section{REFERENCES}

Alberghina L (2007) Systems biology: definitions and perspectives. In Systems Biology; A Grand Challenge for Europe, $\mathrm{R}$ van Driel (Ed), pp 8-9. Strasbourg, France: European Science Foundation

Ausubel DP (1968) Educational Psychology: A Cognitive View. New York, NY, USA: Holt, Rinehart \& Winston

Balmain A, Gray J, Ponder BA (2003) The genetics and genomics of cancer. Nat Genet 33: 238-244

Bennet J, Lubben F, Hogarth S (2006) Bridging science to life: a synthesis of the effects of context-based and STS approaches to science teaching. Science Education 91: 347-369

Boote J, Telford R, Cooper C (2002) Consumer involvement in health research: a review and research agenda. Health Policy 61: 213-236

Caron-Flinterman JF (2005) A New Voice in Science. Patient Participation in DecisionMaking on Biomedical Research. (PhD Thesis) Vrije Universiteit, Amsterdam, the Netherlands Clement J (2000) Model based learning as a key research area for science education. International Journal of Science Education 22: 1041-1053

Collins F (2003) The Future of Genomics. Testimony Before the Subcommittee on Health Committee on Energy and Commerce. Washington, DC, USA: House of Representatives, May 22

Kitcher P (2001) Science, Truth and Democracy. Oxford, UK: Oxford University Press

Knippels MCPJ (2002) Coping with the Abstract and Complex Nature of Genetics in Biology Education. The Yo-Yo Learning and Teaching Strategy. Utrecht, the Netherlands: CB- $\beta$

Knippels MCPJ, Van der Rijst E, Severiens S (2006) De Reizende DNA Labs. Een Evaluatie van vijf Innovatieve Onderwijsmodules. Rotterdam, the Netherlands: Risbo

Latour B (1987) Science in Action: How to Follow Scientists and Engineers Through Society. Milton Keynes, UK: Open University Press

Miller S (2001) Public understanding of science at the crossroads. Public Understanding of Science 10: $115-120$

Moore A (2007) New Biology for New Curricula. Observations from the 6th International Workshop on Science Education 17-19 May 2007. Heidelberg, Germany: European Molecular Biology Organization
NGI (2006) Stragic Plan Genomics 2008-2012. The Hague, the Netherlands: Netherlands Genomics Initiative. www.genomics.nl

Nowotny H, Scott P, Gibbons M (2001) Rethinking Science: Knowledge in an Age of Uncertainty. Cambridge, UK: Polity

RMO (2004) Recommendation 29: Humane Genetica en Samenleving. Bouwstenen voor een Ander Debat. Den Haag, the Netherlands: Raad voor Maatschappelijke Ontwikkeling

Schaefer G (1989) Systems Thinking in Biology Education. Science and Technology Education Document Series 33. Paris, France: UNESCO

Sense about Science Trust (2008) Making sense of testing. London, UK: Sense about Science Trust

Smits G, Waas B (2000) Biologie Voor Jou VWO. Den Bosch, the Netherlands: Malmberg

van der Auweraert A (2004) Dimensions of science communication. Barcelona, Spain: PCST-8 Conference, 3-6 June. www.pcst2004.org van Mil MHW (2007) DNA labs on the road. Science in School 6: 55-58

Verhoeff RP (2003) Towards Systems Thinking in Cell Biology Education. Utrecht, the Netherlands: $C D-\beta$

Verhoeff RP, Waarlo AJ, Boersma KTh (2008) Systems modelling and the development of coherent understanding of cell biology. International Journal of Science Education 30: 543-568

Von Bertalanffy L (1968) General System Theory; Foundations, Development, Applications. New York, NY, USA: George Braziller

Wells S (2006) Deep Ancestry: Inside the Genographic Project. Washington, DC, USA: National Geographic Society
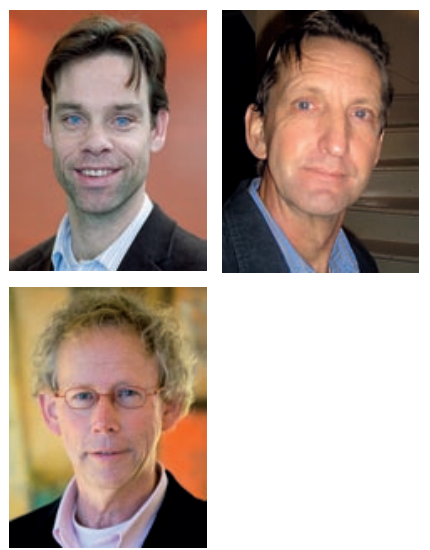

Roald Verhoeff (top left), Dirk Jan Boerwinkel (top right) \& Arend Jan Waarlo are at the Freudenthal Institute for Science and Mathematics Education, Utrecht University, Utrecht, the Netherlands. Roald Verhoeff is also at the Institute for Science, Innovation \& Society at Radboud University, Nijmegen, the Netherlands. This article results from a joint research project of the Cancer Genomics Centre, Utrecht, the Netherlands, and the Centre for Society \& Genomics, Radboud University.

E-mail: r.verhoeff@science.ru.nl

doi:10.1038/embor.2008.254

Published online 23 January 2009 